\title{
Mastering the Art of English Communication Via Listening
}

\author{
S. Sreejana \\ Kumaraguru College of Technology, Coimbatore, Tamil Nadu, India
}

\section{ABSTRACT}

English Communication plays a vital role in this fast-paced competitive working environment. Coming to the four skills of any language: Listening, Speaking, Reading, and Writing; it is correctly said that listening is the foremost one that everyone follows in the initial stage of communication and language acquisition. This paper demonstrates on how listening to English language strengthens one's vocabulary, pronunciation, fluency, confidence and thereby taste the fruit of success. This paper also demonstrates on how distractions and emotional triggers affect students listening. Various listening activities have been introduced to the students to make them feel comfortable and confident in listening and thereby prepare the students to succeed in developing English communication personally and professionally. This research study proves how active listening helps in preventing the problems to escalate and saves time and energy thereby leading to better results in the enhancement of Communication.

KEY WORDS: LISTENING, COMMUNICATION SKILL, LANGUAGE ACQUISITION, CONFIDENCE BUILDING, PRONUNCIATION.

\section{INTRODUCTION}

Listening, like reading, writing, and speaking, is a complex process best developed by consistent practice. Listening is the vital skill providing the basis for the successful communication and successful professional career. Effective listening skills enhance the ability to learn and adapt new information, knowledge, and skills (Liubiniene, V., 2009). Listening is the primary factor that everyone follows in the initial stage of communication and language acquisition. To learn any new language, it is an important factor that listening well to that particular language is essential. When it comes to speaking English language also, the same applies. One's ability to speak English will be improved when the ability to listen is improved. Even before starting conversation, exposure to the language will be more if one listens frequently to the language. There has been a constant move from a purely linguistic listening perception towards one which includes many aspects and facets in relation to the cultural constructs, topic familiarity, discourse clues and pragmatic conventions (Hinkel, 2006).

Biosc Biotech Res Comm P-ISSN: 0974-6455 E-ISSN: 2321-4007

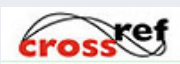

Identifiers and Pagination

Year: 2021 Vol: 14 No (8) Special Issue

Pages: 52-56

This is an open access article under Creative

Commons License Attribn 4.0 Intl (CC-BY).

DOI: $h t t p: / / d x$.doi.org/10.21786/bbrc/14.8.12
Purpose Of The Study: This research has been performed to master the art of English communication skills of the students through listening skills. To improve speaking and writing which are productive skills, listening and reading which are the receptive skills are important. When the students listen actively, they will come across various vocabulary, usage of phrases in day-to-day conversation, the tone and pronunciation of words and so on. The students will acquire new words and phrases through active listening. Vocabulary is a critical element of language composition and development of language knowledge and skills (Cameron, 2001). A conventional listening comprehension lesson simply adds yet another text to the learners' experience; it does little or nothing to improve the effectiveness of their listening or to address their shortcomings as listeners. Teachers focus upon the outcomes of listening, rather than upon listening itself, upon product rather than process" (Field, 1998, 111). Unless the students cultivate the habit of active listening, the simple day to day words and technical terms will be new to them. Therefore, the purpose of this research study is to improve active listening skills among students and thereby acquire good English communication skills.

Research Participants: The study has been conducted for the first year Engineering students to discuss on the problems the students encounter with listening and suggest solution to the problems in listening and thereby improve language acquisition. This research study has been applied in the class of 58 students who have had
Article Information

Received: $25^{\text {th }}$ Apr 2021

ccepted after revision: $15^{\text {th }}$ June 2021 
their studies either in English or Non-English medium schools in and outside Tamilnadu.

Background Study: It has been noted that many students struggle to converse and convey their thoughts in English. To enhance their communication, it has been decided to check where lies the gap. The students were not sound in their pronunciation, vocabulary, and fluency. They seem to be with lack of confidence when they were given an opportunity to convey their thoughts and ideas through speaking. To improve their communication skills, listening is very important as a first step. Therefore, it has been decided to give importance to listening skills and make the students listen actively to the English language. Listening activities have been given to the students to make the class interesting and interactive to acquire language and gain confidence in communication. As a first step, these students have been asked to fill up five general questions relating to their listening.

They were asked basic questions as follows:

1. Do you like to listen to the talks of other people?

2. Would you like to listen to the talks in English language or your regional language?

3. Do you block out distractions when you listen?

4. Do you remember what you hear?

5. Does your mind wander when you listen?

4.1 Listening to the Talks of Other People - Likes and Dislikes: Out of 58 students, 42 students answered that they like to listen to the talks of other people. Remaining 16 students mentioned that they do not like listening. Fig. 1 shows that 72\% of the students are interested in listening to the talks of other people whereas remaining $28 \%$ of the students do not like listening to the talks of people.

Figure: 4.1 Percentage of Students who like and dislike to listen

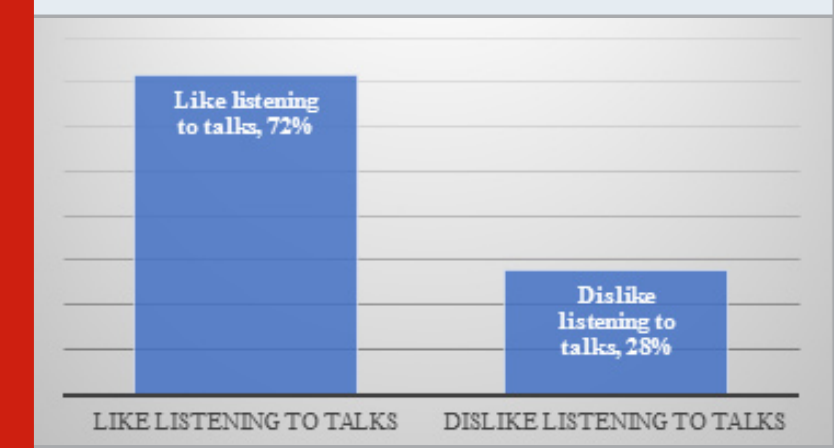

4.2 The Language in which the Students Like to Listen: Generally, when the students are asked whether they like to listen to talks in English or their regional language, it has been noted that $41 \%$ of the students like to listen in English language whereas 59\% of the students are interested to listen in their regional language.

4.3 Blocking Out Distraction when Listening: During the background study, when the students were asked whether they can block their distracting factors during listening process, $27 \%$ of the students mentioned that sometimes they are able to block distractions when they listen whereas $16 \%$ of the students mentioned that usually it is possible for them to block distractions during their listening. The majority of 57\% of the students mentioned that they are not very often able to block out distractions when they are under the process of listening.

Figure: 4.2 Percentage of Students who like to listen to English Language and Regional Language

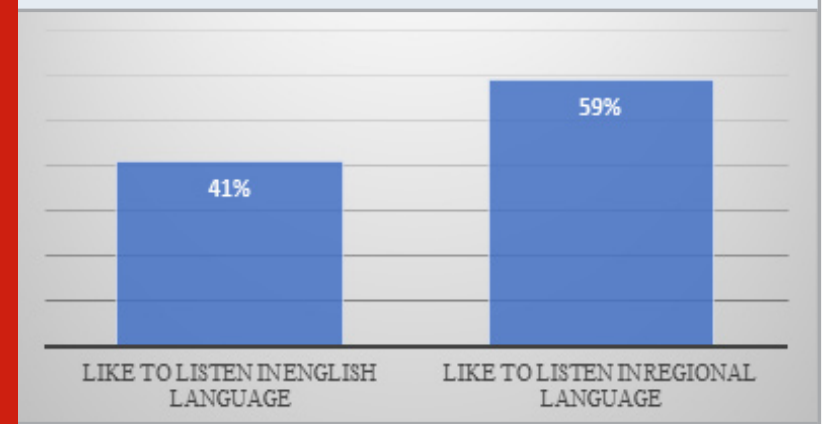

Figure: 4.3 Percentage of Students who block out distractions sometimes/usually/very often when they listen

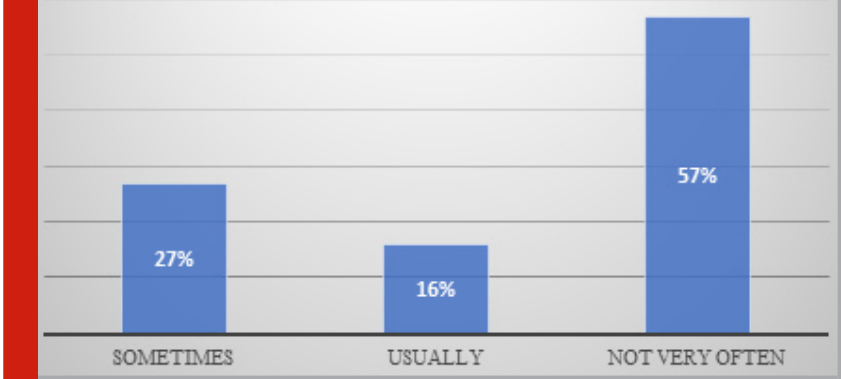

4.4 Remembering whatever is heard: Students were asked whether they can remember whatever they hear. The majority of $48 \%$ of the students recorded that they do not remember very often what they hear. 32\% of the students recorded that sometimes they remember what they hear and 20\% of the students mentioned that usually they remember what they hear.

Figure: 4.4 Percentage of Students who can remember sometimes/usually/very often what they hear

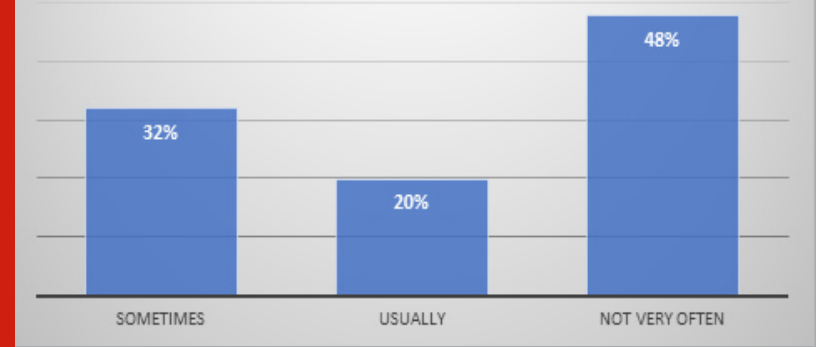


4.5. Wandering of Mind During Listening: When the students were asked whether their mind wanders when they are in the process of listening, it has been noted that $32 \%$ of the students' mind wanders sometimes whereas $12 \%$ of the students' mind wanders not very often during their listening process. It has been noted that the majority of 56\% of the students' mind usually wanders during their listening.

Figure: 4.5 Percentage of Students whose mind wanders sometimes/usually/very often while listening

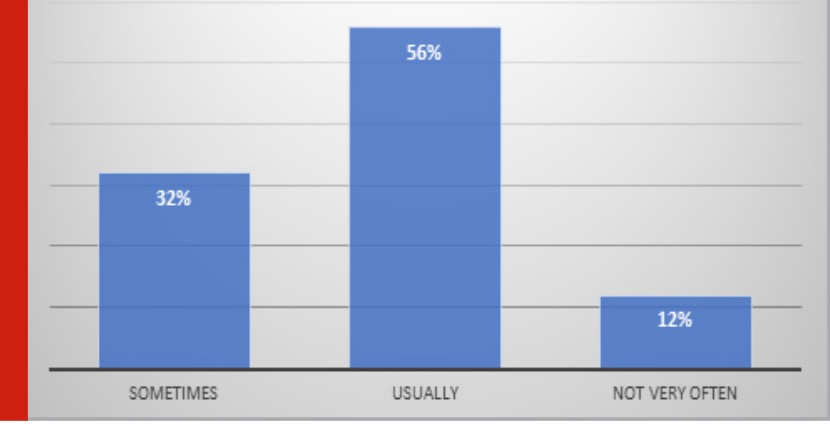

Yagang (1993) reports that listening comes through four variables: the message, the speaker, the listener and the physical setting. Students have many problems in listening. Underwood (1989) organizes the major problems as follows:

- lack of control over the speed at which speakers speak,

- not being able to get things repeated,

- the listener's limited vocabulary,

- failure to recognize the "signals,"

- problems of interpretation,

- inability to concentrate,

- established learning habits.

Hypothesis: Listening skills of the first year Engineering students can be enhanced through activity-based listening practice inside the classroom and thereby English communication skills can be improved personally and professionally in the academic and social scenario.

Research Design and Method: Teaching English to Engineers is a delicate and demanding matter in terms of content, methods and techniques and deciding which is appropriate for this particular area of Engineering and English (Reimer, 2002). Creativity and innovation are becoming increasingly important for the development of the 21st century knowledge society, (Rus, D., 2020). 58 students were divided into 7 teams: 5 teams with 8 members and 2 teams with 9 members. In order to improve the listening skills of the students, activity-based methodology and innovative teaching was focussed. A detailed analysis was done about the listening skills of the students.

Performed Activities to Improve the Listening Skills: By being innovative and creative, it would facilitate in generating curiosity among the learners by extending out pioneering ideas and techniques thus making the progression of learning trouble-free, uncomplicated to comprehend and excitement crammed. The following team activities were conducted in the class of 58 in order to develop the listening skills of the students and there by improve English communication skills.

\subsubsection{Listening to the talks of experts and creating story} or song: During the primary discussion it was noted that the students like to listen to the talks of other people but only if the topic is of their interest, they tend to listen. Otherwise, they switch over to the one that interests them. To make the students attentively listen to any talks of people, the students were given listening group activity which seemed to be interesting. Each team of students were assigned to listen to the talk of various speakers. After they listen, they were asked to create a story of their own as a group by having the listened concept as hint for their creative story. The students were given the liberty to create any story related to the topic that they have listened. It could be a hilarious story, or a tragic note, or a rap song. Here, whether it was interesting or non-interesting speech, the students were expected to listen to the speech, imagine and create a new story without missing the crux of the listened speech.

\subsubsection{Listening to English language and speaking} dialogues: During the survey questionnaire, it was noted that most of the students like to listen to their native language rather than the second language English. In order to make the students interested to listen to English language, students were made to watch and listen to various videos which is of 2 to 3 minutes duration. The videos were humorous short clips. For each team one selected video was played thrice. The teams were expected to play the roles of characters. After playing the video thrice, the students were given time for discussion and preparation for five minutes. After preparation, the video was played again in mute mode, the fourth time. Here, the students were expected to speak the dialogues of the characters as such it was in the video. The video was played thrice in order to make the students observe the characters, understand the concept and humour, memorize the dialogues, manage the dialogue flow in the stipulated time duration. Here all the students were made to listen to the English language. In order to make the language interesting to listen, the videos were selected which covered good humorous concepts.

6.1.3. Listening Activity to Block Out Distraction: During the back ground study, the majority of 57\% of the students mentioned that they are not very often able to block out distractions when they are in listening process. An activity was given to students in order to block out their distractions while listening. To concentrate on listening meticulously, a listening activity was given with the script of conversation where many words were taken off and the students were expected to fill the missing words in the blanks as they listen. Only if the students listened to the conversation meticulously, they 
would be able to fill the blanks without missing the words. The audio was played only once and the blanks were given more.

\subsubsection{Listening to the process and preparing an object:} Each team was given a listening activity which is in the form of instruction and process. The students were expected to listen to the process of making various objects. Each team was given each audio of object preparation process and they were expected to prepare the object by listening to the step-by-step process. The students were given newspaper to prepare the object. This activity was given in order to listen to the audio and remember whatever is heard.

Findings: Listening activities conducted in class for the students helped them in acquiring English language. It also enhanced the mental ability of students and helped them in focusing clearly upon their activity and thereby grasp the language rapidly.

7.1. Listening to the talks of experts and creating story or song: While the advancement in technology has impacted every field across the universe, one of the main things to benefit out of that is must-see media. All the 7 teams were analysed, and it was noted that all the teams were able to bring out their best in the activity. Teaching the skills of listening through this activity helped the students in understanding the contexts well and acquire the language easily. This approach developed creativity, active teamwork with the attitude of creating the best story, narrating skills, making decision, discussing opinion and the skill of communicating the created story to the class. Acquiring language and communicating the created story with confidence became easier due to the activity-based listening. This activity also helped the students to remember whatever is heard. Students' participation for this activity was more when compared to that of simply making the students to listen.

\subsection{Listening to English language and speaking dialogue} script: For this activity, it was noted that $69 \%$ of students were interested in speaking the dialogues of the characters. It was found that the memory power of the students improved where the students were expected to focus on the dialogues, mainly the time duration and fixing their dialogues while the video is in mute mode. $31 \%$ of the students were hesitant to come forward in speaking the dialogues since they had stage fear. Those students also were motivated to speak the dialogues by giving them confidence and motivating them to speak by giving extra time for preparation. These hesitant students were teamed as one team and they were given the video listening and watching for 5 times and they were given the preparation time of 15 minutes. Since everybody in this team is hesitant to speak, they were given more time for preparation and instilled confidence.

They became mentally prepared to speak out since they were given a chance and platform to speak again and sort of compulsion to speak out. Since there were no confident speakers and good communicators in this team, these students were in a compelled state to speak out their dialogues and play the roles. When these students started and ended the activity, it was found that their confidence level improved when comparing to the previous session, and they were able to overcome the stage fear at least 20 to $25 \%$ as a first step. These students were also given another video and asked to prepare and also play the characters with dialogues and they were given an extra chance to speak and also overcome stage fear. Even though these students started their dialogues due to compulsion in speaking, in the end of this activity session, the students improved their confidence level and overcame the stage fear. Due to this extra effort put on to the students, the students were able to overcome their hesitation is speaking.

Figure 1 Listening to the Process and Preparing an Object - Students Participation

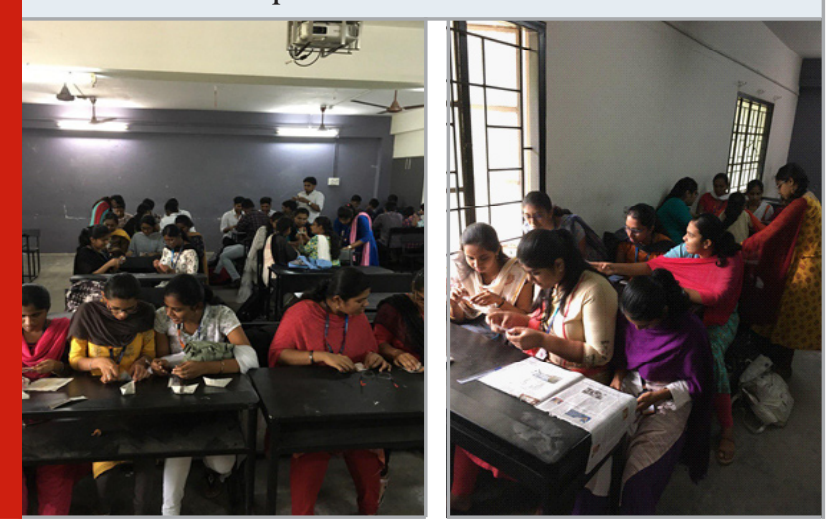

7.3 Listening Activity to Block Out Distraction: For this activity, the students were expected to meticulously listen to the audio and fill the gaps. Interesting listening audios were selected for this activity. Before starting the actual activity, one trial version was done to make the students understand the way how to listen keen and answer. After the trial version, when the activity was done full-fledged, it was noted that the students were interested in filling the blanks meticulously. Here, this activity helped the students to block out distractions and concentrate well in listening. It was noted that 86 $\%$ of the students were able to concentrate well and fill the blanks correctly. 14\% of the students had errors in filling the blanks. It was due to their inability to predict the words and understanding the pronunciation. Because of this, they tend to use another spelling for the similar pronounced words and thereby errors occurred. But even these students were able to concentrate well in their listening even if they had minor errors in spellings. The students were able to overcome the wandering of mind during listening, through this activity and they were able to concentrate well.

7.4 Listening to the process and preparing an Object: Here, for this activity, the students listened well without any distractions. In order to remember the process, the audio was played twice. Here, the students got opportunity to remember whatever they heard and immediately take it into practice of preparing the object 
mentioned in the listening activity. It was noted that all the teams actively involved in the process of making objects by listening to the process. Here the students discussed the preparation of the object they listened and came up with correct object.

\section{CONCLUSION}

The following conclusions were derived after the thorough assessment of the study. Regular listening practice supported in enhancing the listening skill and further improve language proficiency. In the activity-oriented teaching, it was evident that majority of the students were successful in all the activities. This methodology aided the students to enhance their language skills, decision making, narrating skills, overcome stage fear, creativity, discussion and so on. The activities directed to them demonstrated to be an entertaining boost up to expose their listening skills. The common reasons for the unsuccessful students in few activities were the poor capacity in understanding and interpreting the audio. Another factor was that the students were not able to relate their learning with the activity that was assigned to them. Also, there was experience and exposure lagging in them and inability to predict and decide. It was also noted that their thought flow to relate the content was lagging. The main thing noticed was the level of confidence which was lagging and poor discussion and decision-making skill.

These students when they were given frequent practice of listening were able to stand one step ahead in their listening ability and thereby improve their communication skill. Having a close watch and taking steps to overcome these conditions will help the students to improve their listening ability. A methodical approach to focus on these conditions will facilitate offering appropriate platform on which the students can work up on to improve their listening skills and thereby improve English Communication. If the field of weakness is identified in the initial stage, it will help in offering correct guidance for the students to improve their listening skills in a right way and thereby developing communication skills. To enhance communication skills of the students through listening, the methodology mentioned in this study will prove to be a successful remedy for the teachers of English to make the students practice in class.

\section{REFERENCES}

Cameron, L. (2001). Teaching languages to young learners. Ernst Klett Sprachen.

Field, J. (1998). Skills and strategies: Towards a new methodology for listening. ELT Journal, 52(2), 111.

Hinkel, Eli. (2006). Current perspectives on teaching the four skills. TESOL Quarterly, 40(1).

Liubiniene, V. (2009). Developing listening skills in CLI. Kalbc studijos, (15), 89-93.

Reimer, Marc J. (2002), "English and Communication Skills for Global Engineer", Global Journal of Engineering Education, 6 (1), 9.3.

Rus, D. (2020). Creative Methodologies in Teaching English for Engineering Students. Procedia Manufacturing, 46, 337-343.

Sreejana, S., (2019). English Mass Media: The WorldWide Knowledge Bank for Learners. International Journal of Recent Technology and Engineering, 7, 1820.

Sreejana, S., (2019). Farewell to Orator-Listener Mode of Teaching and Welcome to The Role as Language Engineers. International Journal of Recent Technology and Engineering, 7, 1-4.

Underwood, M., \&t Kenworthy, J. (1989). Teaching listening. M. Rost (Ed.). London: Longman.

Yagang, F. (1993). Listening: Problems and solutions. 